\title{
Ecological Aesthetics in Product Design
}

\author{
Kai You ${ }^{1}$ \\ ${ }^{1}$ GuangDong Polytechnic of Industry and Commerce Guangzhou 510000, China
}

\begin{abstract}
Key words: Product design, Ecological awareness, Ecological aesthetics, Human and nature
\end{abstract}
\begin{abstract}
The main purpose of product design is to help people to solve various problems in life and satisfy people's demands in material aspects and spiritual aspects. In order to answer the nation's scientific development strategic deployment of loving nature, protecting nature and living in harmony with nature, product designers are required to not only satisfy people's basic demands of the product, but also consider the close relationship between human beings and nature when designing products. Product design should establish ecological awareness. However, with the rapid development of Chinese economic society and the quick development of industrialization, large amount of products that go against green natural ecology exist in people's life. Human beings just ask for things from nature and ecological unbalance happened, which brought severe influences on sustainable development. Therefore, the concept of ecological aesthetics should be integrated to product design so as to realize the harmony between human and nature. This paper explains the significance and importance of ecological aesthetics in product design and introduces application of product design in ecological aesthetics.

Before the industrial revolution, product design in human society was mainly traditional handicraft. Since there was no modern machinery production, handicrafts mainly relied on labor force. Therefore, human activities had little impact on ecological environment and human beings lived in harmony with nature. However, with the development of industrialization, in modern industrial civilization, bourgeoisie proposed the slogan of "utilizing nature and transforming nature" and conducted business and industry product, which led to people's pursuit of asking for natural resources, excessive utilization of natural resources and ecological unbalance. Therefore, large amount of natural disasters because of ecological unbalance happened. Later, destruction to natural ecological environment has been catching people's attention. With the progress of the society and development of social civilization, people's life views, world outlook and values have changed and their attitude to nature has also changed; they realized the importance of ecological civilization as well as the importance of the harmony between human and nature, and they created the ideology of ecological aesthetics. Ecological aesthetics gradually becomes an important basic element that modern designers must consider to design products.
\end{abstract}

\section{Basis and significance of ecological aesthetics in product design}

Ecological aesthetics has narrow and generalized senses. The narrow one refers to a harmonious relationship between human and nature; the generalized explanation means on the basis of satisfying people's basic demands, the close relationship between human and nature should be considered and the social aesthetics that observes ecological rules fundamentally. As a new concept, ecological aesthetics not only has profound natural and scientific thoughts, but also advanced philosophical thoughts. It not only reflects necessary demands of human life, but also the aesthetic views of natural ecology and human comfort.

With the development of large-scale industrialization production, Western old brand bourgeoisie conducted industrial manufacturing with the slogan of "utilizing nature and transforming nature" while destruction to ecological environment has influenced people's daily life gradually. John · Ruskin, a famous British artist, proposed the slogan of "returning to nature", emphasizing that we should not transform nature by violence during product design process; instead, we should utilize natural forms as much as possible, comply with natural rules so as to protect development of natural ecology. However, because of the powerful momentum of industrial wave, this proposition was submerged in the roars of large machinery. However, the proposal of this ideology by 
John·Ruskin had profound enlightening significance to later generations of product design philosophy. This idea was the cornerstone of product aesthetics ecological design. With the development of modern society, natural and ecological problems have caught people's comprehensive attention. People realized that human and nature supplemented each other and human cannot destroy nature randomly. In the meantime, people found that they could treat natural ecological product as an aesthetic object and natural ecological beauty as the yard stick of product design. This scientific thought treats ecological aesthetics as object, promotes the harmonious relationship between human and nature and builds natural and beautiful ecological environment people live.

\section{Embodiment of ecological aesthetics in modern products}

Meaning of ecological aesthetics in product design. Product design is a comprehensive science, including chemistry, physics, astronomy, geography, biology, sociology, and aesthetics and so on. Therefore, its comprehensiveness degree is very high and it is artistic and technological integration that solves people's material demands and spiritual demands in daily life. With the development of industrialization, the importance of ecological aesthetics in people's life improves gradually. In modern society, people's living environment is under increasingly severe "big industrialization" development. Therefore, more and more people began to pay attention to ecological aesthetics. People have realized the importance of the harmony between human and nature. In natural ecological balanced development, we can treat the most natural matter as an aesthetic object to seek ecological environment suitable for human's survival.

Ecology and aesthetics supplement each other and influence each other, thereby forming ecological aesthetics. Ecology is a natural science that studies all living organisms on earth and their living environment. Aesthetics is a philosophical science studying the relationship between human aesthetics and reality. The combination of the two is the joint point of the combination between human, nature and environment and ecological aesthetics is the special joint point.

The importance of ecological aesthetics in product design. Chinese ancient philosopher Laozi advocated the harmony between human and nature, emphasizing that ecological system was uniform and could not be destructed. Laozi advocated Dow process unity; he believed that the origin of the world was Tao and "the Tao way follows nature", "The way bears sensation, sensation bears memory, sensation and memory bear abstraction, and abstraction bears all the world." Modern ecological aesthetics proposes new demands on product design, stressing the systematicness and ecology of human and natural ecological system. This demand reveals the relationship that human and nature rely on each other and supplement each other. Ecological aesthetics in product design is to realize the transformation from technical beauty to natural beauty rather than pure natural beauty and this process needs to be produced by human beings.

Chinese ecological aesthetics originated from the middle of the 1990s, when product design manifested traditional virtues of Chinese nation mostly, i.e., the beautiful realm of peaceful coexistence of human and nature. At the beginning of the reform and opening up, Chinese economic society developed at a tremendous pace, industrial design such as manufacturing industry replaced handwork gradually, which was similar to the development process of Western society, and rough development disadvantages appeared. However, with the continuous growth of Chinese national economy, people's living standard improved continuously and people were no longer satisfied with pursuit for material life, they began to pay more attention to spiritual pursuit. In the past, when people were purchasing products, they merely paid attention to their functions and appearance; now, they pay more attention to ecological aesthetics in product design so as to satisfy spiritual requirements.

With the rapid development of the society, modern living pace also accelerates. People are bearing pressure from various aspects. Since the pressure is nowhere to release, people's spiritual world needs to be enriched continuously and more and more people gradually realized the importance of returning to nature. In daily life, people's demands for industrial products are indispensable. In order to satisfy people's beautiful wish of returning to nature, designers combined 
ecological aesthetics with product design. Compared with traditional industrial products, these products are more natural and simple compared with traditional industrial products, and they can integrate into people' life more easily. They seem to become the sustenance of people's emotions. Through product design, designers explore their potential natural beauty, call for people to protect ecological environment and the harmonious relationship between human and nature.

The realization of ecological aesthetics in product design. There are various species and living creatures in nature. During product design process, people can treat these species as the design elements of ecological aesthetics, and they can extract the characteristics and forms of these matters combining their cognition and understanding as well as deliver ecological beauty with creative language. The integration of ecological aesthetics and product design can be realized from the mode, principle and semantic layers of different species. Aesthetics is an important issue in ecological aesthetics. The combination of product design and ecological aesthetics and be considered from the following aspects:

Combination of ecological model forms and products. The so-called combination of ecological model forms and products means imitating living creatures in models and appearance in product design process or integrating product combinations such as natural colors or natural texture in product forms. For example, various bionics designs in Tetrarch studio and Masanori Umeda, a well-known contemporary Japanese designer, designed a rose chair that took the form of a flower, which gave people fresh feelings and represented natural beauty. For example, the Italian brand Alessi; all its products use lively and active colors as well as design elements full of fun. When people are using them, they can also feel the relaxed and joyful ecological interests and people's emotional demands can be satisfied. This kind of products is novel and has long vitality. Besides Tetrarch studio, products from British designer William Morris factory are also designed in the way of modeling forms. For example, the chairs and artistic lamps all adopt the texture of animals and plants as decorations and they advocate choice of materials and imitating nature.

Combination of product design and ecological technology. The combination of product design and ecological technology take advantage of advanced science and technology, advanced materials and processing technology. On the basis of realizing product functions, it can reduce production's destruction to natural environment to the maximum. The essence of this design philosophy of integrating product design and ecological technology is to realize zero waste and zero pollution of products in production process based on existing aesthetics with environmental protection as aesthetic standard. It makes people truly experience the sense of mission from the coexistence of human and nature during the using process as well as the pride of applying this philosophy into practice. For example, a cup from Makiko Nakamura, a Japanese ceramics artist. He adopted hollow double-deck design and arranged little holes on the outside layer of the ceramic cup, just like the ventilating holes from which marmots came out. This design can not only dissipate the heat, but also strengthen friction so that the holding feeling is good. If boiled water is poured in, the user does not have to worry about being burned.

This scientific and novel design can attract consumers' attention easily. Take another case for example, sharp-skin — a new one-piece swimsuit designed by world famous swimsuit manufacturer Speedo Company. This swimsuit is especially designed according to the theory that scales on the skin of sharks can help the sharks to swim in water. It turns out that this sharp-skin can help athletes to reduce resistance during swimming.

Semantic combination of product design and ecology. People always say "Inner beauty is true beauty", and ecological aesthetics in product design has the functions of cultivating one's sentiment and enlightening one's heart. During the aesthetic process, people transform natural things to their true feelings and pursuit for beauty so that they can combine themselves with nature closely, release pressure and ease their mind. When designers are designing products, they can build a natural and ecological beautiful mind from different aspects, which are using forms, using functions and using methods; in the meantime, they can also make users feel the charm of ecological beauty so as to arouse people's feelings of ecological nature, be close to nature from the bottom of their heart, return to nature and live in harmony with nature. For example, a fruit drink packaging designed by 
Naoto Fukasawa Company. The design uses rubber, which can express the design meaning of bananas, oranges, apples and so on sufficiently. When people see the packaging of the drinks, it seems that they can feel the taste of the fruits. In the meantime, people would want to touch the packaging. In the addition, it is easy to differentiate the flavor of the drinks.

\section{Conclusion}

All in all, ecological aesthetics is based on the contact point of the harmony between human and nature, human and society, society and nature. How designers represent natural beauty in product design is the key of ecological beauty. Only be integrating ecological beauty with products and let the users feel the charm of ecological beauty in the using process can we awaken the consciousness of ecological nature and burst out the beautiful wish of being close to nature, returning to nature and living in harmony with nature. Today, when social industrialization develops rapidly, we should be more aware of the important significance of ecological beauty in product design, integrate ecological beauty into product design skillfully and bring more enlightenment to people's life so that the whole society can realize the harmony between human and nature.

\section{References}

[1] C.S. Yang. On Inter-subjectivity of Ecological Beauty. Study on Aesthetics, 2006.25-54 (In Chinese)

[2] Z. H. Gao. Theoretical Background and Philosophical Views on Ecological Beauty. Jiangsu Social Sciences, 2004.(2)10-13 (In Chinese)

[3] Y. Z. Li Beauty of Creating - Art and Culture of Product Design, Beijing, Renmin University of China Press, 2009.15-57 (In Chinese)

[4] Q. Dong. Contribution of Ecological Public Benefit Natural Process to Human, Applied Ecology, 2007.10(2)233-240 (In Chinese)

[5] Z.B. Huang and Z.F. Liu, Contemporary Ecological Philosophy and Green Design Methodology, Anhui, Anhui Renmin Press, 2004.21-65 (In Chinese) 